\title{
Garcinia indica as an Environmentally Safe Corrosion Inhibitor for Aluminium in 0.5 M Phosphoric Acid
}

\author{
Deepa Prabhu and Padmalatha Rao \\ Department of Chemistry, Manipal Institute of Technology, Manipal University, Karnataka 576104, India \\ Correspondence should be addressed to Padmalatha Rao; drpadmalatharao@yahoo.com
}

Received 28 July 2013; Revised 31 October 2013; Accepted 1 November 2013

Academic Editor: W. Ke

Copyright (C) 2013 D. Prabhu and P. Rao. This is an open access article distributed under the Creative Commons Attribution License, which permits unrestricted use, distribution, and reproduction in any medium, provided the original work is properly cited.

\begin{abstract}
The Inhibitive and adsorption properties of aqueous extract of seeds of Garcinia indica extract (GIE) have been studied for corrosion control of aluminium in $0.5 \mathrm{M}$ phosphoric acid solution using potentiodynamic polarization and electrochemical impedance spectroscopy (EIS) techniques at $30^{\circ} \mathrm{C}$ to $50^{\circ} \mathrm{C}$. The effects of inhibitor concentration on the inhibition action were investigated. Polarization measurements showed that the GIE acted as mixed inhibitor and the inhibitor molecules followed chemical adsorption on the surface of aluminium. The adsorption of GIE on metal surface obeyed Langmuir adsorption isotherm. The surface morphology of aluminium, in the absence and in the presence of GIE in $0.5 \mathrm{M}$ phosphoric acid solution, was studied using scanning electron microscopy (SEM). Results obtained from both of the electrochemical techniques were in good agreement with each other.
\end{abstract}

\section{Introduction}

Aluminium is the most commonly used metal in power transmission and the metallurgy of nonferrous metals due to its high-electrical conductivity, good working and forming properties, lightness, ease of recycling, low density, ductility, and high-mechanical strength $[1,2]$. Aluminium and most of the aluminium alloys have good corrosion resistance towards natural atmosphere and other environments, because aluminium surfaces are covered with a natural oxide film. In the presence of aggressive environment the protective layer can be locally destroyed and corrosive attack takes place. Solutions of phosphoric acid are frequently employed for cleaning of aluminium [3] and in commercial preplating anodic oxidation and electropolishing of aluminium [4]. Phosphoric acid is most preferred for metal cleaning than hydrochloric [5] or sulphuric acid because of lower dissolution of metal in phosphoric acid medium. Even though dissolution rate of aluminium in phosphoric acid is lower, it is not at all negligible [6]. Therefore, it is necessary to use inhibitors for the corrosion of aluminium in phosphoric acid solution [7-10].

Among the numerous organic compounds that have been tested and are applied industrially as corrosion inhibitors, those that are nontoxic are now far more strategic than in the recent past [7-11]. In the past two decades the research in the field of green inhibitors has been addressed toward the goal of using cheap, effective molecules at low or zero environmental impact [12-18]. In an attempt to find corrosion inhibitors that are environmentally safe and readily available, there has been a growing trend in the use of natural products such as plants extracts as corrosion inhibitors for metals in acid-cleaning process [19-21].

As a part of our studies on the corrosion inhibition of aluminium and 6063 aluminium alloy in acidic medium using plant extracts $[22,23]$ we report herein the results of using aqueous extract of Garcinia indica seed as a novel green inhibitor for corrosion control of aluminium in $0.5 \mathrm{M}$ phosphoric acid solution.

Garcinia indica, a plant in the mangosteen family (Clusiaceae), is a fruit-bearing tree that has culinary, pharmaceutical, and industrial uses. Seeds of Garcinia indica contain several organic compounds that are biodegradable and ecologically acceptable [24]; thus it is selected for the present investigation. The objective of the present work is extended to investigate the inhibition effect of Garcinia indica on the corrosion of aluminum in $\mathrm{H}_{3} \mathrm{PO}_{4}$ solutions for the first time by potentiodynamic polarization curves, electrochemical impedance spectroscopy (EIS), and scanning electron microscopy (SEM) methods. Effects of inhibitor 
concentration and temperature on the corrosion inhibition were investigated. The adsorption and inhibition effect of GIE on aluminum in $\mathrm{H}_{3} \mathrm{PO}_{4}$ solutions are discussed.

\section{Experimental}

2.1. Material. The commercially available sample of aluminium was used for the study. The specimen contains $99.61 \%$ aluminium with $0.27 \%$ iron and $0.12 \%$ silicon.

2.2. Medium. Stock solution of $0.5 \mathrm{M}$ phosphoric acid was prepared by diluting AR grade phosphoric acid (85\%) with double distilled water and was standardized by potentiometric method.

2.3. Preparation of Test Coupons. Cylindrical test coupon was sealed with acrylic resin material in such a way that the area exposed to the medium was $0.7 \mathrm{~cm}^{2}$. The disc was polished with $180,280,400,600,800,1000,1500$, and 2000 grade emery papers and further polished with disc polisher using levigated alumina till mirror surface was obtained. It was dried and stored in a desiccator to avoid moisture before being used for corrosion studies.

2.4. Preparation and Characterization of Garcinia indica Extract (GIE). A sample of the powder $(25 \mathrm{~g})$ was refluxed in $250 \mathrm{~mL}$ of water at $90^{\circ} \mathrm{C}$ for $3 \mathrm{~h}$. The refluxed solution was kept overnight, filtered, and the filter liquor was evaporated to dryness. Then the deep brown-reddish solid residue was obtained and preserved in a desiccator. It was used to prepare the inhibitor solution of required strength in distilled water. The concentration range of GIE used was 100-500 ppm.

FTIR spectra of the dried sample were recorded using spectrophotometer (Shimadz Model) in the frequency range of 4000 to $400 \mathrm{~cm}^{-1}$ using $\mathrm{KBr}$ pellet technique.

2.5. Electrochemical Measurements. Electrochemical measurements were carried out by using an electrochemical work station, (CH600D-series, U.S. Model with $\mathrm{CH}$ instrument beta software). The electrochemical cell used was a conventional three-electrode compartment having glass cell with a platinum counter electrode and a saturated calomel electrode (SCE) as reference. The working electrode was made up of aluminium. All the values of potential were with reference to the SCE. The polarization studies were carried out immediately after the EIS studies on the same electrode without any further surface treatment.

2.6. Tafel Polarization Studies. Finely polished specimens were exposed to the corrosion medium of $0.5 \mathrm{M}$ phosphoric acid solution in the absence and in the presence of the inhibitor at different temperatures $\left(30^{\circ} \mathrm{C}\right.$ to $\left.50^{\circ} \mathrm{C}\right)$ and allowed to establish a steady-state open circuit potential (OCP) for approximately $30 \mathrm{~min}$. The potentiodynamic currentpotential curves were recorded by polarizing the specimen to $-250 \mathrm{mV}$ cathodically and $+250 \mathrm{mV}$ anodically with respect to the OCP at a scan rate of $1 \mathrm{mV} \mathrm{s}^{-1}$.
2.7. Electrochemical Impedance Spectroscopy (EIS) Studies. The impedance measurements were carried out in the frequency range from $100 \mathrm{kHz}$ to $0.01 \mathrm{~Hz}$, at the rest potential, by applying $10 \mathrm{mV}$ sine wave $\mathrm{AC}$ voltage. The impedance data were analyzed using Nyquist plots. The charge transfer resistance, $R_{\mathrm{ct}}$, was extracted from the diameter of the semicircle in Nyquist plot.

In all the above mentioned measurements, at least three similar results were considered and their average values are reported.

2.8. Scanning Electron Microscopy (SEM) Studies. The surface morphology of the aluminium specimen immersed in $0.5 \mathrm{M}$ $\mathrm{H}_{3} \mathrm{PO}_{4}$ solution in the presence and the absence of inhibitor was compared by recording the SEM images of the samples using EVO MA18.

\section{Results and Discussion}

3.1. Fourier Transform Infrared (FTIR) Spectroscopy of GIE. Figure 1 shows the FTIR spectroscopy of GIE. -OH stretching frequency appears at $3396.41 \mathrm{~cm}^{-1}$. The aromatic stretching frequency appears at $2923.88 \mathrm{~cm}^{-1}$. $-\mathrm{C}=\mathrm{O}-$ stretching frequency is at $1785.96 \mathrm{~cm}^{-1} .-\mathrm{C}=\mathrm{C}$ - stretching frequency is at $1608.52 \mathrm{~cm}^{-1}$. $-\mathrm{CH}_{2}$ bending frequency is at $1446.51 \mathrm{~cm}^{-1}$. $-\mathrm{C}-\mathrm{H}$ bending frequency is at $1282.57 \mathrm{~cm}^{-1}$. $-\mathrm{C}-\mathrm{O}$ bending frequency is at $1099.35 \mathrm{~cm}^{-1}$.

3.2. Tafel Polarization Measurement. The effect of GIE on the corrosion reactions was determined by polarization techniques. The changes observed in the polarization curves after the addition of the inhibitor are usually used as the criteria to classify inhibitors as cathodic, anodic, or mixed $[25,26]$.

Figure 2 shows the Tafel polarization curves for aluminium in $0.5 \mathrm{M}$ phosphoric acid solution at different concentrations of inhibitor at $30^{\circ} \mathrm{C}$. Similar results were obtained at other temperatures as well.

Inhibitor efficiency was calculated using

$$
\eta(\%)=\frac{i_{\text {corr }}-i_{\text {corr }(\mathrm{inh})}}{i_{\text {corr }}} \times 100,
$$

where $i_{\text {corr }}$ and $i_{\text {corr (inh) }}$ are the corrosion current densities obtained in uninhibited and inhibited solutions, respectively. The corrosion rate was calculated using

$$
v_{\text {corr }}\left(\mathrm{mmy}^{-1}\right)=\frac{3270 \times M \times i_{\text {corr }}}{\rho \times Z},
$$

where 3270 is a constant that defines the unit of corrosion rate, $i_{\text {corr }}$ is the corrosion current density in $\mathrm{A} \mathrm{cm}^{-2}, \rho$ is the density of the corroding material $\left(\mathrm{g} \mathrm{cm}^{-3}\right), M$ is the atomic mass of the metal, and $Z$ is the number of electrons transferred per atom $[27,28]$.

The valuable potentiodynamic polarization parameters such as corrosion potential $\left(E_{\text {corr }}\right)$, cathodic and anodic Tafel slopes $\left(b_{c}\right.$ and $\left.b_{a}\right)$, corrosion current density $\left(i_{\text {corr }}\right)$ and 


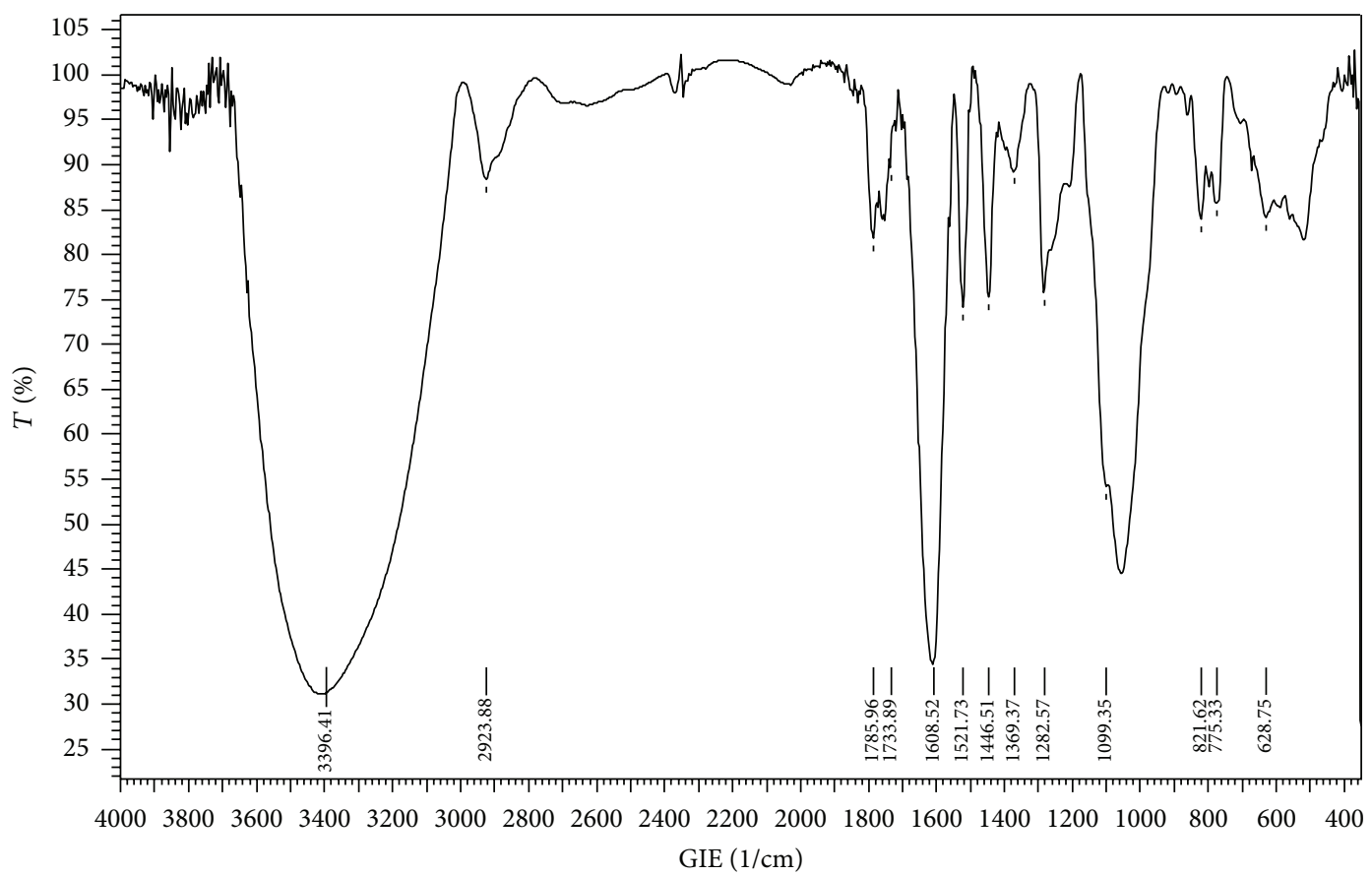

FIGURE 1: FTIR spectrum of GIE.

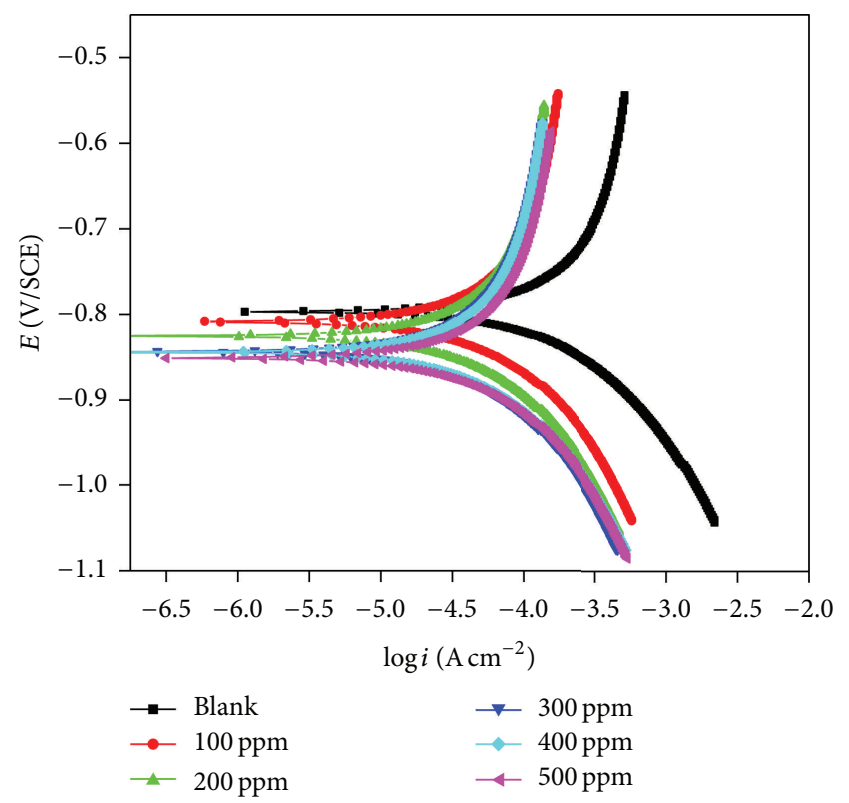

FIgURE 2: Tafel polarization curves for aluminum in $0.5 \mathrm{M}$ phosphoric acid solution at different concentrations of inhibitor (CSE) at $30^{\circ} \mathrm{C}$.

corrosion rate (CR) were obtained from Tafel plots. The inhibition efficiency values $\eta(\%)$ were calculated using (1). The results are tabulated in Table 1 . It is obvious that corrosion current density decreases with increase in the concentration of the inhibitor.

From Figure 2 and Table 1, it can be observed that the addition of GIE at all the studied concentrations resulted in the significant decrease in the corrosion current density $\left(i_{\text {corr }}\right)$ and decrease in the corrosion rate. It is also evident that the percentage efficiency of the inhibitor increased with increase in the concentration of the inhibitor. Percentage efficiency of the inhibitor also increased with increase in temperature. There was no remarkable shift in the corrosion potential $\left(E_{\text {corr }}\right)$ value with respect to the blank. According to the literature report $[28,29]$, when corrosion potential is more than $\pm 85 \mathrm{mV}$ with respect to the corrosion potential of the blank, the inhibitor can be considered distinctively as either cathodic or anodic type. However, the maximum displacement in this study is less than $\pm 85 \mathrm{mV}$. This suggests that GIE functions as mixed-type inhibitor.

There is a slight change in the anodic and cathodic slopes after the addition of the inhibitor. The parallel cathodic Tafel curves suggest that the hydrogen evolution is activation controlled, and the reduction mechanism is not affected by the presence of the inhibitor. The shift in the anodic Tafel slope may be due to the surface/inhibitor molecules adsorbed on the metal surface.

3.3. Electrochemical Impedance Spectroscopy (EIS) Studies. The results of the Tafel polarization method were compared with the results of impedance measurements. EIS measurements were carried out at different temperatures at different inhibitor concentrations. The Nyquist plots of aluminium in $0.5 \mathrm{M}$ phosphoric acid containing various concentrations of inhibitor are shown in Figure 3.

Impedance plots are semicircles both in the absence and in the presence of the inhibitor. The diameter of the capacitive loop increased with increase in the concentration of the inhibitor. This indicated that the impedance of 
TABLE 1: Results of Tafel polarization studies on aluminum in $0.5 \mathrm{M}$ phosphoric acid solution containing different concentrations of inhibitor GIE.

\begin{tabular}{|c|c|c|c|c|c|c|c|}
\hline $\begin{array}{l}\text { Temp. } \\
\left({ }^{\circ} \mathrm{C}\right)\end{array}$ & $\begin{array}{l}\text { Conc. of inhibitor } \\
(\mathrm{ppm})\end{array}$ & $\begin{array}{c}E_{\text {corr }} \\
(\mathrm{mV} \text { versus SCE) }\end{array}$ & $\begin{array}{c}i_{\text {corr }} \\
\left(\times \mathrm{m} \mathrm{cm}^{-2}\right)\end{array}$ & $\begin{array}{c}-b_{c} \\
\left(\mathrm{mV} \operatorname{dec}^{-1}\right)\end{array}$ & $\begin{array}{c}b_{a} \\
\left(\mathrm{mV} \mathrm{dec}^{-1}\right)\end{array}$ & $\begin{array}{c}\mathrm{CR} \\
\left(\mathrm{mm} \mathrm{y}^{-1}\right)\end{array}$ & $\begin{array}{c}\eta \\
(\%) \\
\end{array}$ \\
\hline \multirow{6}{*}{30} & Blank & -797 & 0.17 & 637 & 354 & 1.89 & - \\
\hline & 100 & -795 & 0.09 & 626 & 356 & 1.03 & 45.33 \\
\hline & 200 & -805 & 0.08 & 634 & 346 & 0.91 & 51.96 \\
\hline & 300 & -772 & 0.08 & 611 & 361 & 0.85 & 54.77 \\
\hline & 400 & -801 & 0.06 & 686 & 333 & 0.70 & 62.99 \\
\hline & 500 & -785 & 0.06 & 664 & 346 & 0.63 & 66.58 \\
\hline \multirow{6}{*}{35} & Blank & -793 & 0.22 & 610 & 353 & 2.39 & - \\
\hline & 100 & -788 & 0.11 & 641 & 367 & 1.18 & 50.64 \\
\hline & 200 & -779 & 0.10 & 674 & 342 & 1.06 & 55.66 \\
\hline & 300 & -796 & 0.09 & 668 & 365 & 0.96 & 59.68 \\
\hline & 400 & -796 & 0.07 & 685 & 353 & 0.80 & 66.70 \\
\hline & 500 & -764 & 0.06 & 632 & 319 & 0.71 & 70.37 \\
\hline \multirow{6}{*}{40} & Blank & -797 & 0.28 & 596 & 364 & 3.00 & - \\
\hline & 100 & -774 & 0.12 & 615 & 374 & 1.34 & 55.38 \\
\hline & 200 & -789 & 0.11 & 621 & 373 & 1.16 & 61.30 \\
\hline & 300 & -796 & 0.10 & 642 & 371 & 1.06 & 64.56 \\
\hline & 400 & -777 & 0.08 & 670 & 321 & 0.84 & 72.15 \\
\hline & 500 & -769 & 0.07 & 655 & 299 & 0.75 & 75.17 \\
\hline \multirow{6}{*}{45} & Blank & -804 & 0.40 & 595 & 367 & 4.38 & - \\
\hline & 100 & -797 & 0.16 & 578 & 397 & 1.75 & 60.04 \\
\hline & 200 & -799 & 0.14 & 616 & 380 & 1.49 & 66.01 \\
\hline & 300 & -793 & 0.11 & 642 & 380 & 1.24 & 71.70 \\
\hline & 400 & -780 & 0.10 & 716 & 312 & 1.14 & 74.03 \\
\hline & 500 & -665 & 0.08 & 546 & 264 & 0.84 & 80.84 \\
\hline \multirow{6}{*}{50} & Blank & -800 & 0.48 & 579 & 379 & 5.20 & - \\
\hline & 100 & -765 & 0.16 & 573 & 370 & 1.73 & 66.75 \\
\hline & 200 & -806 & 0.14 & 586 & 396 & 1.56 & 70.09 \\
\hline & 300 & -810 & 0.12 & 595 & 392 & 1.28 & 75.38 \\
\hline & 400 & -738 & 0.09 & 609 & 366 & 1.02 & 80.44 \\
\hline & 500 & -639 & 0.07 & 616 & 343 & 0.75 & 85.59 \\
\hline
\end{tabular}

the inhibited substrate increased with the inhibitor concentration. The impedance plots have a large capacitive loop at higher frequencies (HF), small inductive loop at intermediate frequencies (IF), followed by a second capacitive loop at low frequency (LF) value for uninhibited surface. Under inhibited conditions Nyquist plot consists of a large capacitive loop at high frequencies (HF) and an inductive loop at low frequencies (LF). Absence of additional inductive loop at intermediate frequency after the addition of inhibitor suggests the adsorption of inhibitor molecule, which changes the mechanism at the interface. The capacitive loop at HF is related to the charge transfer of the corrosion process and the double layer behavior [30]. It was also observed that addition of the inhibitor does not change the shape of the semicircle, indicating that there is absolutely no charge transfer taking place due to the addition of inhibitor.
The high frequency capacitive loop could be assigned to the charge transfer of the corrosion process and to the formation of oxide layer [30]. The oxide film is considered to be a parallel circuit of a resistor due to the ionic conduction in the oxide film and a capacitor due to its dielectric properties. The capacitive loop is corresponding to the interfacial reactions, particularly the reaction of aluminium oxidation at the metal/oxide/electrolyte interface [31]. The process includes the formation of $\mathrm{Al}^{+}$ions at the metal/oxide interface and their migration through the oxide/solution interface where they are oxidized to $\mathrm{Al}^{3+}$. At the oxide/solution interface, $\mathrm{OH}^{-}$or $\mathrm{O}^{2-}$ ions are also formed. The fact that all the three processes are represented by only one loop could be attributed either to the overlapping of the loops of processes or to the assumption that one process only dominates, excluding 


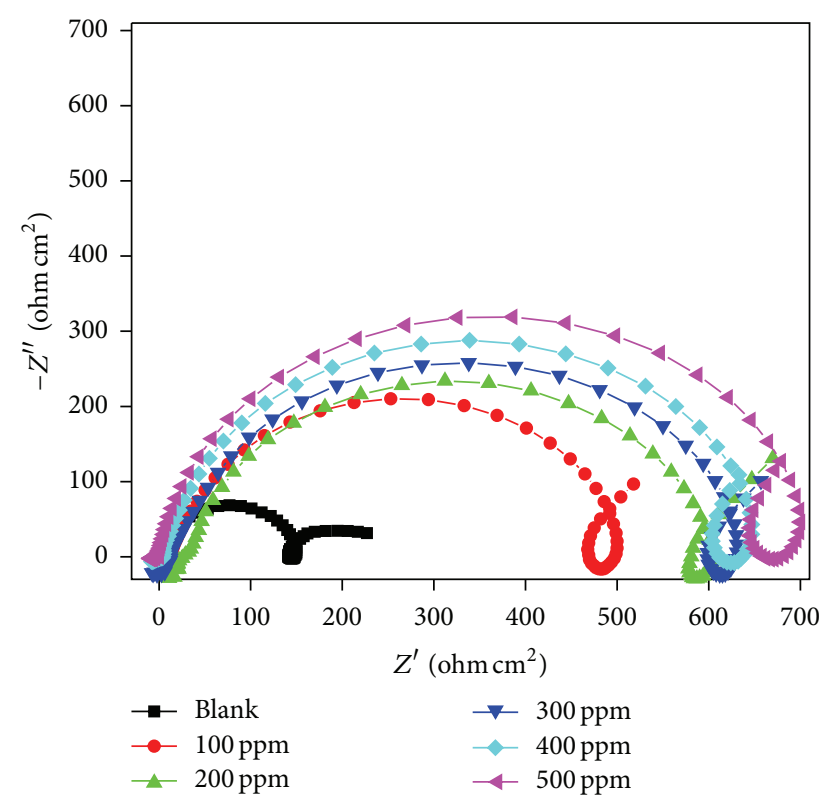

FIGURE 3: Nyquist plots and equivalent circuit for the corrosion of aluminum in $0.5 \mathrm{M}$ phosphoric acid solution containing different concentrations of inhibitor (GIE) at $30^{\circ} \mathrm{C}$.

the other processes. The other explanation offered to the high frequency capacitive loop is the oxide film itself. The origin of the inductive loop has often been attributed to surface or bulk relaxation of species in the oxide layer [31]. The LF inductive loop may be related to the relaxation process obtained by adsorption and incorporation of phosphate ions, oxide ions, and charged intermediates on and into the oxide film. The second capacitive loop observed at LF values could be assigned to the metal dissolution.

The fact that all the three processes are represented by only one loop could be attributed either to the overlapping of the loops of processes or to the assumption that one process dominates and, therefore, excludes the other processes $[32,33]$. The other explanation offered to the high frequency capacitive loop is the oxide film itself. The origin of the inductive loop has often been attributed to surface or bulk relaxation of species in the oxide layer [34]. The LF inductive loop may be related to the relaxation process obtained by adsorption and incorporation of phosphate ions on and into the oxide film [35].

An equivalent circuit of nine elements depicted in Figure 4(a) was used to simulate the measured impedance data of aluminium. The explanation given for the Nyquist plots is shown in Figure 4(b). In this equivalent circuit $R_{s}$ is the solution resistance and $R_{\mathrm{ct}}$ is the charge transfer resistance. $R_{L}$ and $L$ represent the inductive elements. This also consists of constant phase element: CPE (Q) in parallel with the series capacitors $C_{1}, C_{2}$ and series resistors $R_{1}, R_{2}$, $R_{L}$, and $R_{\mathrm{ct}}$. $R_{L}$ is parallel with the inductor $L$.

The polarization resistance $R_{p}$ and double layer capacitance $C_{\mathrm{dl}}$ can be calculated from

$$
\begin{gathered}
R_{p}=R_{L}+R_{\mathrm{ct}}+R_{1}+R_{2}, \\
C_{\mathrm{dl}}=C_{1}+C_{2} .
\end{gathered}
$$

TABLE 2: Electrochemical impedance values of aluminum in $0.5 \mathrm{M}$ phosphoric acid solution containing different concentrations of

\begin{tabular}{|c|c|c|c|c|}
\hline $\begin{array}{l}T \\
\left({ }^{\circ} \mathrm{C}\right)\end{array}$ & $\begin{array}{l}\text { Conc. } \\
\text { (ppm) }\end{array}$ & $\begin{array}{c}R_{p} \\
\left(\Omega \mathrm{cm}^{2}\right)\end{array}$ & $\begin{array}{c}\mathrm{CPE} \\
\left(\mu \mathrm{F} \mathrm{cm}^{-2}\right)\end{array}$ & $\begin{array}{c}\eta \\
(\%)\end{array}$ \\
\hline \multirow{6}{*}{30} & 0 & 241.30 & 15 & - \\
\hline & 100 & 411.38 & 14 & 41.34 \\
\hline & 200 & 462.29 & 12 & 47.80 \\
\hline & 300 & 493.50 & 11 & 51.10 \\
\hline & 400 & 641.99 & 9 & 62.41 \\
\hline & 500 & 712.02 & 8 & 66.11 \\
\hline \multirow{6}{*}{35} & 0 & 195.90 & 26 & - \\
\hline & 100 & 386.88 & 24 & 49.36 \\
\hline & 200 & 431.81 & 22 & 54.63 \\
\hline & 300 & 475.86 & 18 & 58.83 \\
\hline & 400 & 578.29 & 17 & 66.12 \\
\hline & 500 & 651.15 & 15 & 69.91 \\
\hline \multirow{6}{*}{40} & 0 & 154.20 & 32 & - \\
\hline & 100 & 335.58 & 30 & 54.05 \\
\hline & 200 & 388.45 & 28 & 60.30 \\
\hline & 300 & 425.10 & 25 & 63.73 \\
\hline & 400 & 543.68 & 23 & 71.64 \\
\hline & 500 & 611.02 & 20 & 74.76 \\
\hline \multirow{6}{*}{45} & 0 & 102.40 & 46 & - \\
\hline & 100 & 246.26 & 43 & 58.42 \\
\hline & 200 & 291.27 & 39 & 64.84 \\
\hline & 300 & 351.84 & 35 & 70.90 \\
\hline & 400 & 384.30 & 33 & 73.35 \\
\hline & 500 & 524.45 & 30 & 80.47 \\
\hline \multirow{6}{*}{50} & 0 & 85.10 & 58 & - \\
\hline & 100 & 245.64 & 46 & 65.40 \\
\hline & 200 & 274.19 & 43 & 69.00 \\
\hline & 300 & 335.25 & 37 & 74.65 \\
\hline & 400 & 424.56 & 34 & 79.98 \\
\hline & 500 & 579.87 & 31 & 85.34 \\
\hline
\end{tabular}
inhibitor (GIE) at different temperatures.

The circuit fitment was done by ZSimpWin software version 3.21. The results obtained from this are tabulated in Table 2 . The CPE is composed of a component $Q_{\mathrm{dl}}$ and a coefficient " $a$ " which quantifies different physical phenomena like surface inhomogeneous resulting from surface roughness, inhibitor adsorption, porous layer formation, and so forth $[18]$. The parameter " $a$ " quantifies different physical phenomena like surface inhomogeneousness resulting from surface roughness and so forth [32].

The bode plots (bode phase plots and bode magnitude plots) obtained at OCP for aluminium in the presence and absence of inhibitor containing $0.5 \mathrm{M}$ phosphoric acid obtained at $30^{\circ} \mathrm{C}$ are presented in Figures 5 and 6, respectively. It is apparent that, the values of phase increase with increase in concentration of added GIE up to their optimal concentration. The bode magnitude plots indicate the presence of 


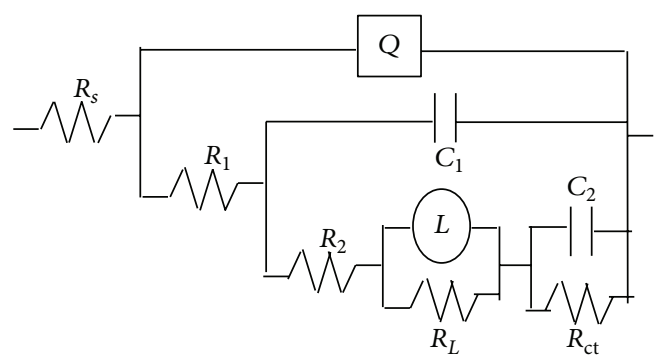

(a)

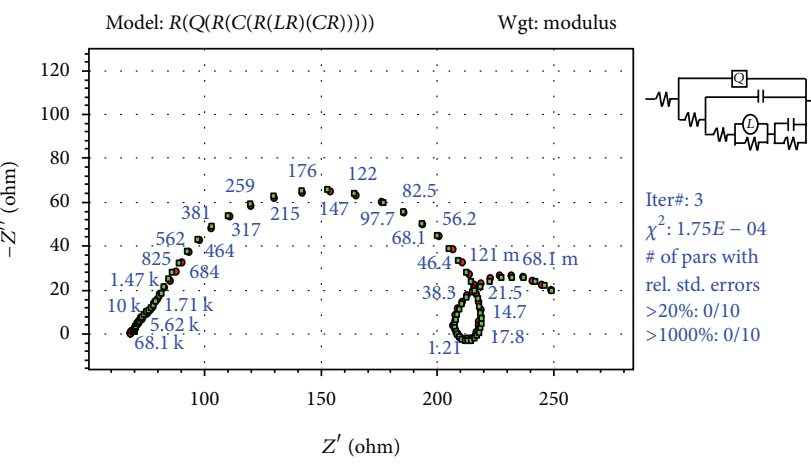

- $Z$, msd.

- $Z$, calc.

(b)

FIGURE 4: (a) Equivalent circuit used to fit the experimental EIS data. (b) EIS data obtained for the corrosion of aluminum specimen in phosphoric acid at $30^{\circ} \mathrm{C}$.

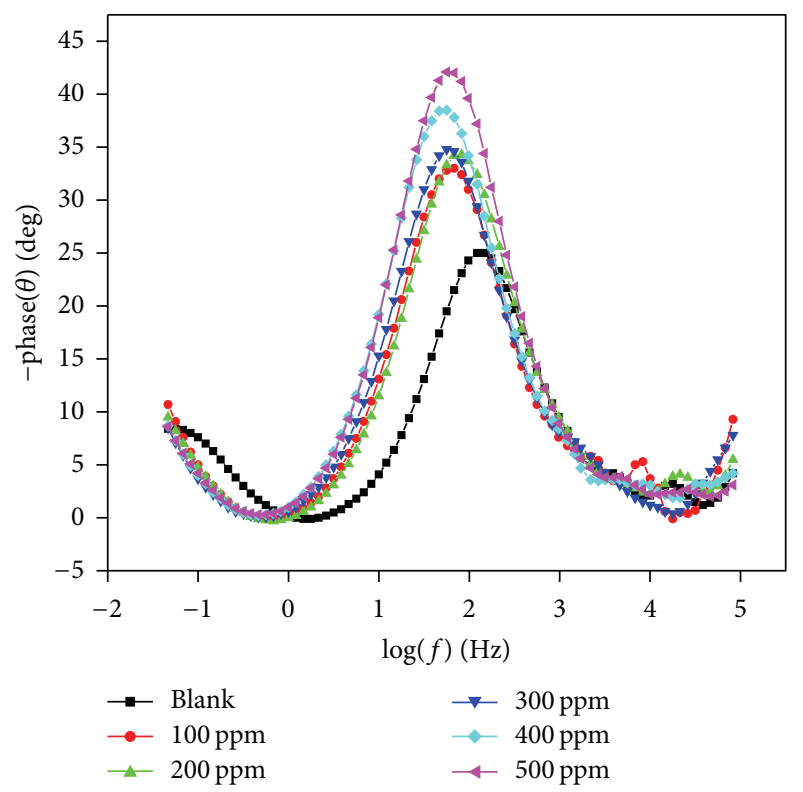

Figure 5: Bode phase plots for the corrosion of aluminium in $0.5 \mathrm{M}$ phosphoric acid at $30^{\circ} \mathrm{C}$ in the presence of different concentrations of GIE.

only one slope for the uninhibited and inhibited systems. The difference between the high frequency (HF) limit and low frequency (LF) limit in the bode plot is equal to $R_{p}$, the polarization resistance, which is associated with the dissolution and repassivation processes occurring at the interface as well as the electronic conductivity of the film. The difference between the HF and LF for the uninhibited and inhibited systems in the bode plot increases with increase in the concentration of GIE up to their critical concentration.

The results of Table 2 indicated that, the $R_{p}$ values increased with the increase in the concentrations of the inhibitor. As the $R_{p}$ value increased, there was a decrease in the $C_{\mathrm{dl}}$ values. Thus effective corrosion resistance was observed to be associated with high $R_{p}$ and low $C_{\mathrm{dl}}$ values [33].

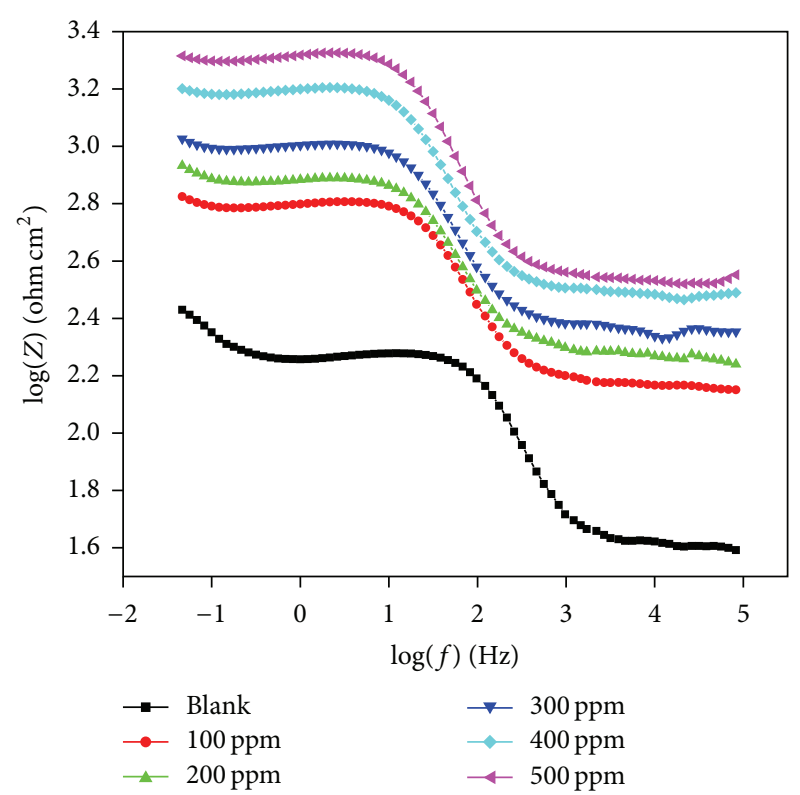

FIGURE 6: Bode magnitude plots for the corrosion of aluminium in $0.5 \mathrm{M}$ phosphoric acid at $30^{\circ} \mathrm{C}$ in the presence of different concentrations of GIE.

Percentage efficiency of the inhibitor is calculated using the following relation:

$$
\eta(\%)=\left(\frac{R_{p(\mathrm{inh})}-R_{p}}{R_{p(\mathrm{inh})}}\right),
$$

where $R_{p \text { (inh) }}$ and $R_{p}$ are the polarization resistances in the presence and absence of inhibitor.

The results of Tafel polarization method and electrochemical impedance method are in good agreement with one another. This proves that corrosion rate depends upon the nature of the inhibitor used and not on the technique employed for measuring the same.

3.4. Effect of Temperature. The study on the effect of temperature on the corrosion rate and inhibition efficiency facilitates 


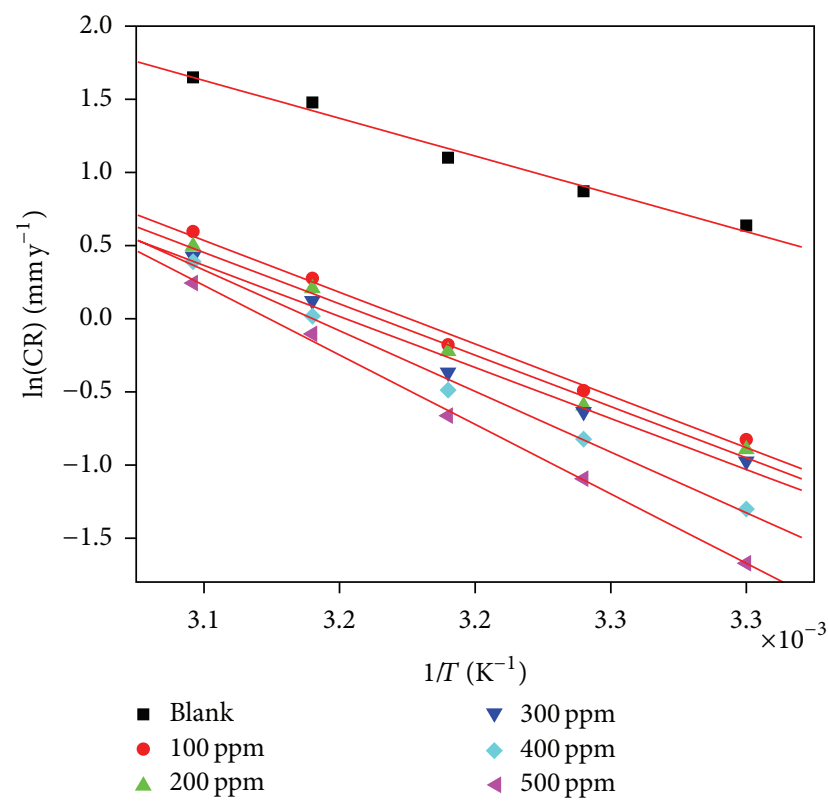

FIGURE 7: Arrhenius plots for the corrosion of aluminum in $0.5 \mathrm{M}$ phosphoric acid containing different concentrations of inhibitor (GIE).

the calculation of kinetic and thermodynamic parameters for the inhibition and the adsorption processes. These parameters are useful in interpreting the type of adsorption by the inhibitor. In the present investigation, the corrosion potential $\left(E_{\text {corr }}\right)$, anodic and cathodic slopes $\left(b_{a}\right.$ and $\left.b_{c}\right)$ are not affected much after the addition of the inhibitor. This indicates that the increase in the temperature does not change the mechanism of the corrosion mechanism. In the present investigation there is an increase in the corrosion efficiency with increase in the temperature. The results reported in Tables 1 and 2 showed that the inhibition efficiency of GIE increases with increase in temperature.

The apparent activation energy $\left(E_{a}\right)$ for the corrosion process in the presence and absence of inhibitor can be calculated $[36,37]$ using the Arrhenius equation:

$$
\ln \left(v_{\text {corr }}\right)=B-\frac{E_{a}}{R T},
$$

where $B$ is a constant which depends on the metal type, $R$ is the universal gas constant, and $T$ is the absolute temperature. The plot of $\ln \left(v_{\text {corr }}\right)$ versus reciprocal of absolute temperature $(1 / T)$ gave a straight line with slope $=-E_{a} / R$, from which the activation energy values for the corrosion and the inhibition processes were calculated. The Arrhenius plots for the corrosion of aluminium in $0.5 \mathrm{M}$ phosphoric acid solution in the absence and in the presence of different concentrations of inhibitor are shown in Figure 7.

The enthalpy of activation $\left(\Delta H^{\#}\right)$ and entropy of activation $\left(\Delta S^{\#}\right)$ for the dissolution of alloy were calculated from the transition state equation [37]:

$$
v_{\text {corr }}=\frac{R T}{N h} \exp \left(\frac{\Delta S^{\#}}{R}\right) \exp \left(\frac{\Delta H^{\#}}{R T}\right),
$$

TABLE 3: Activation parameters for the corrosion of aluminum in $0.5 \mathrm{M}$ phosphoric acid containing different concentrations of inhibitor CSE.

\begin{tabular}{lccc}
\hline $\begin{array}{l}\text { Conc. of inhibitor } \\
(\mathrm{ppm})\end{array}$ & $\begin{array}{c}E_{a} \\
\left(\mathrm{~kJ} \mathrm{~mol}^{-1}\right)\end{array}$ & $\begin{array}{c}\Delta H_{a} \\
\left(\mathrm{~kJ} \mathrm{~mol}^{-1}\right)\end{array}$ & $\begin{array}{c}\Delta S_{a} \\
\left(\mathrm{~J} \mathrm{~mol}^{-1} \mathrm{~K}^{-1}\right)\end{array}$ \\
\hline 0.0 & 45.70 & 43.15 & -56.64 \\
100 & 23.40 & 20.79 & -176.29 \\
200 & 23.23 & 20.62 & -177.91 \\
300 & 18.29 & 14.82 & -197.46 \\
400 & 17.43 & 15.68 & -196.30 \\
500 & 8.69 & 6.08 & -228.52 \\
\hline
\end{tabular}

where $h$ is Plank's constant and $N$ is Avogadro's number. A plot of $\ln \left(v_{\text {corr }} / T\right)$ versus $1 / T$ gives a straight line with slope $=$ $-\Delta H^{\#} / T$ and intercept $=\ln (R / N h)+\Delta S^{\#} / R$.

The plots of $\ln \left(v_{\text {corr }} / T\right)$ versus $1 / T$ for the corrosion of aluminium in the presence of different concentrations of inhibitor are shown in Figure 8. The calculated values of activation parameters are tabulated in Table 3.

From Table 3, it is obvious that the value of activation energy in $0.5 \mathrm{M}$ phosphoric acid solution containing the inhibitor is lower than that without inhibitor. The extent of decrease is proportional to the inhibitor concentration. The decrease in apparent activation energy may be due to chemical adsorption $[38,39]$ of the inhibitor. Increase in the inhibition efficiency with increase in temperature may be attributed to increase in the adsorption of the inhibitor on the metal surface with increase in temperature. Large negative values of entropies show that the activated complex in the rate determining step is an association rather than dissociation step meaning that a decrease in disordering takes place on going from reactants to the activated complex [40].

3.5. Adsorption Behavior. In order to understand the mechanism of corrosion inhibition, the adsorption behavior of the adsorbate on the aluminium surface must be known. The information on the interaction between the inhibitor molecules and the metal surface can be provided by adsorption isotherm. The degree of surface coverage $(\theta)$ for different concentrations of inhibitor was evaluated from potentiodynamic polarization measurements. The data was applied to various isotherms including Langmuir, Temkin, Frumkin, and Flory-Huggins isotherms. It was found that the data best fit the Langmuir adsorption isotherm and can be represented using the following relation [33]:

$$
\frac{C_{\text {inh }}}{\theta}=\frac{1}{K}+C_{\text {inh }}
$$

where $K(\mathrm{~L} / \mathrm{mol})$ is the adsorption/desorption equilibrium constant, $C_{\text {inh }}$ is the corrosion inhibitor concentration in the solution, and $(\theta)$ is the surface coverage, which is calculated using

$$
\theta=\frac{\eta(\%)}{100}
$$

where $\eta(\%)$ is the percentage inhibition efficiency as calculated using (1). The plot of $C_{\mathrm{inh}} / \theta$ versus $C_{\mathrm{inh}}$ gave a straight 


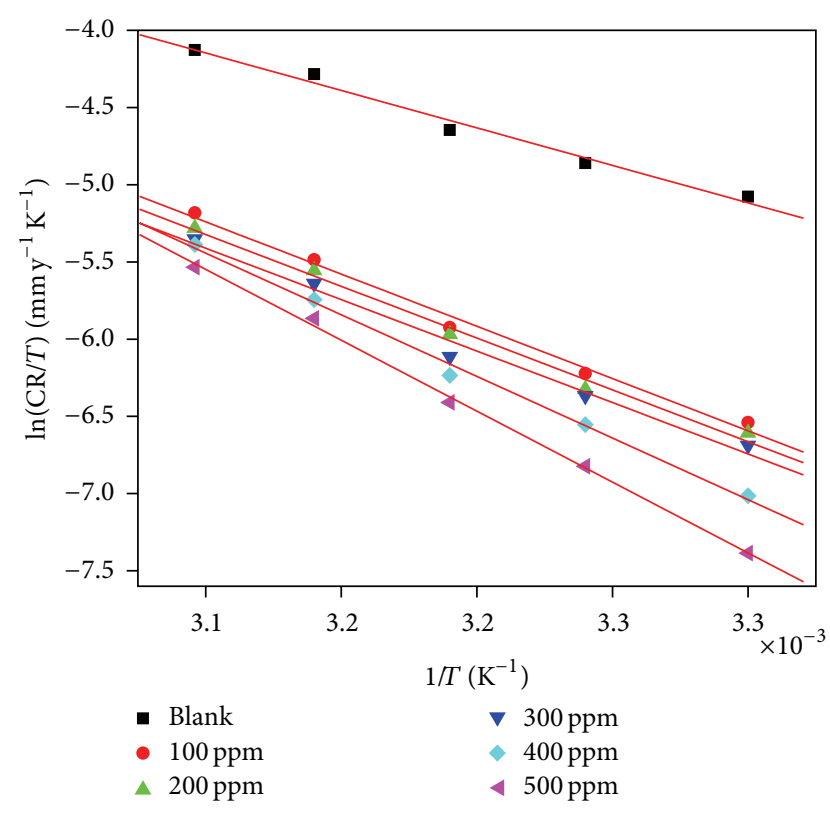

FIGURE 8: Plots of $\ln \left(v_{\text {corr }} / T\right)$ versus $1 / T$ for the corrosion of aluminum in $0.5 \mathrm{M}$ phosphoric acid containing different concentrations of inhibitor (GIE).

line with an intercept of $1 / K$. The Langmuir adsorption isotherms for the adsorption of inhibitor on the aluminium surface are shown in Figure 9.

The slopes of the isotherms show deviation from the value of unity as would be expected for the ideal Langmuir adsorption isotherm equation. This deviation from unity may be due to the interaction among the adsorbed species on the metal surface. The Langmuir isotherm equation is based on the assumption that adsorbed molecules do not interact with one another, but this is not true in the case of organic molecules having polar atoms or groups from heterocyclic compounds which are adsorbed on the cathodic and anodic sites of the metal surface. The values of standard free energy $\left(\Delta G_{\text {ads }}^{0}\right.$ ) of adsorption are related to $K$ by the relation shown in the following equation.

$$
K=\frac{1}{55.5} \exp \left(\frac{-\Delta G_{\mathrm{ads}}^{\circ}}{R T}\right),
$$

where $K(\mathrm{~L} / \mathrm{mol})$ is the adsorption/desorption equilibrium constant, value 55.5 is the concentration of water in solution in $\mathrm{mol} / \mathrm{L}, R$ is the universal gas constant, and $T$ is absolute temperature. The standard enthalpy of adsorption $\left(\Delta H_{\mathrm{ads}}^{0}\right)$ and standard entropy of adsorption $\left(\Delta S_{\text {ads }}^{0}\right)$ were calculated from the plots of $\left(\Delta G_{\mathrm{ads}}^{0}\right)$ versus $T$. The thermodynamic parameters for the adsorption of GIE on the 6063 aluminium alloy are listed in Table 4.

Generally, value of $\Delta G_{\text {ads }}^{0}$ up to $-20 \mathrm{~kJ} \mathrm{~mol}^{-1}$ is consistent with the electrostatic interaction between the charged molecules and the charged metal (physical adsorption) while the value more negative than $-40 \mathrm{~kJ} \mathrm{~mol}^{-1}$ involves sharing or transfer of electrons from the inhibitor molecules to the metal surface to form a coordinate type of bond (chemisorption)
TABLE 4: Thermodynamic parameters for the adsorption of GIE on aluminium in $0.5 \mathrm{M}$ phosphoric acid solution at different temperatures.

\begin{tabular}{lccc}
\hline$T\left({ }^{\circ} \mathrm{C}\right)$ & $\begin{array}{c}-\Delta G_{\mathrm{ads}}^{\circ} \\
\left(\mathrm{kJ} \mathrm{mol}^{-1}\right)\end{array}$ & $\begin{array}{c}\Delta H_{\mathrm{ads}}^{\circ} \\
\left(\mathrm{kJ} \mathrm{mol}^{-1}\right)\end{array}$ & $\begin{array}{c}\Delta S_{\mathrm{ads}}^{\circ} \\
\left(\mathrm{J} \mathrm{mol}^{-1} \mathrm{~K}^{-1}\right)\end{array}$ \\
\hline 303 & 21.08 & & \\
308 & 22.87 & & -184.44 \\
313 & 23.31 & 34.25 & \\
318 & 24.73 & & \\
323 & 25.06 & & \\
\hline
\end{tabular}

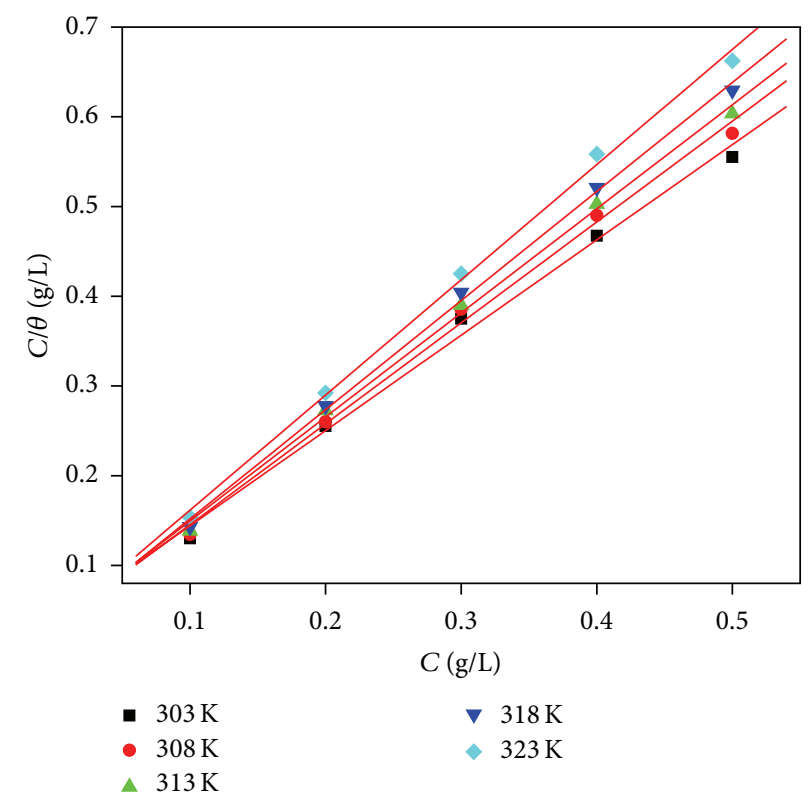

FIGURE 9: Langmuir adsorption isotherms for the adsorption of GIE on aluminum in $0.5 \mathrm{M}$ phosphoric acid solution at different temperatures.

[37]. In the present study, the values of $\Delta G_{\text {ads }}^{0}$ are above $-20 \mathrm{~kJ} \mathrm{~mol}^{-1} \cdot \Delta G_{\text {ads }}^{0}$ and inhibition efficiency increase with the increase in temperature, indicating that the adsorption of GIE on the aluminium surface in phosphoric acid is favoured at high temperature and hence can be considered to be predominantly chemisorption [38]. The positive value of enthalpy of adsorption indicates that the adsorption of the inhibitor molecule is an endothermic process. Generally, an exothermic adsorption process signifies either physical adsorption or chemical adsorption, while the endothermic process is attributable unequivocally to chemical adsorption [39]. In the present investigation positive value of enthalpy of adsorption proves that adsorption of the inhibitor is by a chemical adsorption process. The chemical adsorption is also consistent with the increase in the efficiency of the inhibitor with increase in temperature. The $\Delta S_{\text {ads }}^{0}$ value is large and negative, indicating that the decrease in disordering takes place on going from the reactant to the adsorbed species. This can be attributed to the fact that adsorption is always accompanied by decrease in entropy [37]. 
3.6. Explanation for Inhibition. GIE is composed of numerous naturally occurring compounds. The principal active components of the aqueous extract are Garcinol, Isogarcinol, and Curcumin. The structure of Garcinol is shown in Figure 10.

Aluminium and aluminium alloys have air formed oxide film of amorphous $\gamma$ alumina which initially thickens on exposure to neutral aqueous solution with the formation of crystalline hydrated alumina. In acid solution the mechanism of dissolution of aluminium is as follows [40]:

$$
\begin{gathered}
\mathrm{Al}+\mathrm{H}_{2} \mathrm{O} \longrightarrow \mathrm{AlOH}_{(\text {ads })}+\mathrm{H}^{+}+\mathrm{e}^{-} \\
\mathrm{AlOH}_{(\mathrm{ads})}+5 \mathrm{H}_{2} \mathrm{O}+\mathrm{H}^{+} \longrightarrow \mathrm{Al}^{3+}+6 \mathrm{H}_{2} \mathrm{O}+2 \mathrm{e}^{-} \\
\mathrm{Al}^{3+}+\mathrm{H}_{2} \mathrm{O} \longrightarrow[\mathrm{AlOH}]^{2+}+\mathrm{H}^{+} \\
{[\mathrm{AlOH}]^{2+}+\mathrm{X}^{-} \longrightarrow[\mathrm{AlOHX}]^{+}}
\end{gathered}
$$

Thus soluble complex ion formed leads to the dissolution of the metal. The major cathodic reaction is evolution of hydrogen gas according to the following steps:

$$
\begin{gathered}
\mathrm{H}^{+}+\mathrm{e}^{-} \longrightarrow \mathrm{H}_{(\mathrm{ads})} \\
\mathrm{H}_{(\mathrm{ads})}+\mathrm{H}_{(\mathrm{ads})} \longrightarrow \mathrm{H}_{2}
\end{gathered}
$$

The adsorption of the inhibitor molecule is often a displacement reaction involving removal of adsorbed water molecules from the metal surface [41]:

$$
\text { Inhibitor }_{(\text {sol })}+\mathrm{XH}_{2} \mathrm{O}_{(\mathrm{ads})} \longleftrightarrow \text { Inhibitor }_{(\mathrm{ads})}+\mathrm{XH}_{2} \mathrm{O}_{(\mathrm{sol})}
$$

Polar organic compounds containing sulphur, nitrogen, and oxygen are good corrosion inhibitors. Tannins, which are complex astringent aromatic acidic glycosides found in plants, are made up of polyphenols and their heterocyclic derivatives. The inhibition of GIE is mainly attributed to the presence of Garcinol and other organic compounds in the extract. Garcinol is a large molecule containing various hetero cyclic functional groups like $-\mathrm{OH}$ and $-\mathrm{C}=\mathrm{O}$. These are the centers of high electron density. According to the reported literature natural polyphenolic compounds containing vicinal hydroxyl groups readily form complexes with di-tri-valent metal ions [37, 38]. Thus Garcinol molecule gets chemically adsorbed over the surface of the metal in the anodic area and brings anodic process under control. Further, Garcinol molecules are chemically adsorbed due to interaction of $\pi$ orbitals with metal surface. The large Garcinol molecule may be responsible for the formation of an oriented film layer, which essentially blocks discharge of $\mathrm{H}^{+}$and brings cathodic reaction under control. Garcinol thus acts as a mixed type of inhibitor bringing both anodic and cathodic reactions under control. There will be a formation of a stable layer of the inhibitor molecule on the entire surface of the metal. This stable layer of the inhibitor forms the barrier between the metal and the corrosive environment and controls the rate of corrosion. The inhibitory action of the GIE is therefore explained by the formation of complexes in the form of

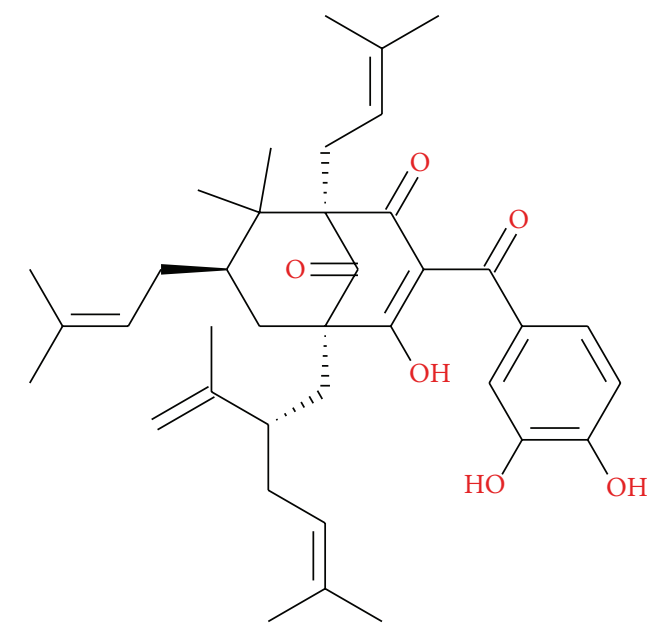

FIGURE 10: Structure of Garcinol.

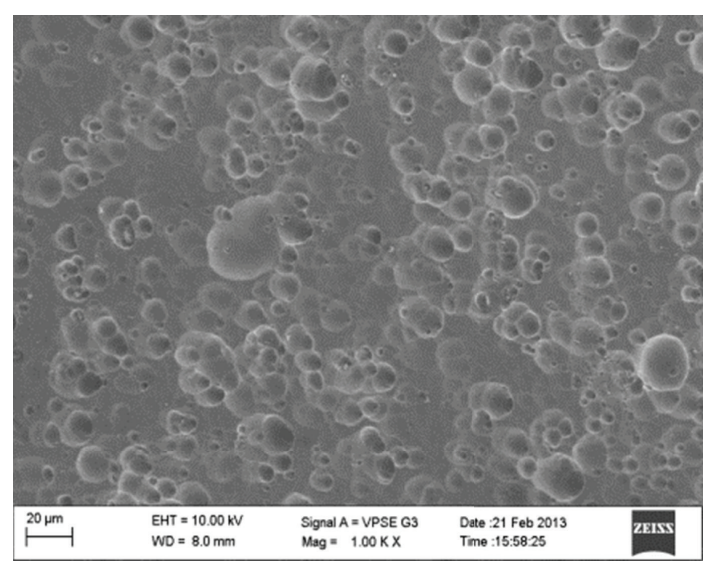

FIGURE 11: SEM image of aluminum after immersion in $0.5 \mathrm{M}$ $\mathrm{H}_{3} \mathrm{PO}_{4}$.

chelates with aluminium ions in the solution and subsequent precipitation of complex formed at the surface of the alloy in the places where oxide film has been destroyed [42].

3.7. SEM Studies. The SEM image of corroded surface of pure aluminium is given in Figure 11. It shows degradation of aluminium, with more or less uniform attack in phosphoric acid. Close observation of SEM images indicates the deposition of precipitates of aluminium phosphate on the surface of aluminium. Figure 12 represents the surface after being treated with GIE inhibitor. The surface of the aluminium has become more clear after the treatment with GIE inhibitor. This confirms the formation of the inhibitor layer on the surface of the metal, which is responsible for the decrease in the corrosion rate.

\section{Conclusions}

Based on the results of investigation, the following conclusions are drawn. 


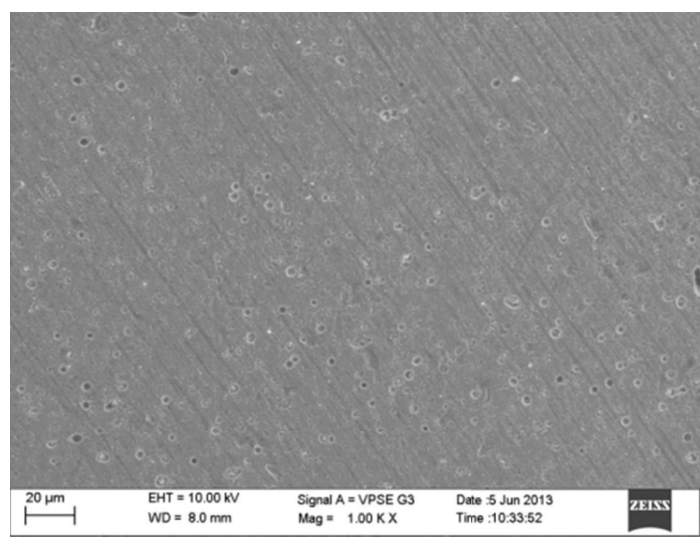

FIGURE 12: SEM image of the surface of aluminum after $0.5 \mathrm{M} \mathrm{H}_{3} \mathrm{PO}_{4}$ at $30^{\circ} \mathrm{C}$ in presence of $500 \mathrm{ppm}$ of GIE.

(1) GIE is a good eco-friendly green inhibitor for the corrosion control of aluminium in $0.5 \mathrm{M}$ phosphoric acid solution.

(2) Inhibition efficiency of the GIE increases with increase in the concentration of the inhibitor and also with temperature.

(3) GIE acts as a mixed inhibitor on the surface of the metal.

(4) GIE gets chemically adsorbed on the surface of aluminium and obeys Langmuir adsorption isotherm.

(5) GIE is a renewable, easily available, cost effective, and environmentally benign inhibitor.

\section{Conflict of Interests}

The authors declare that there is no conflict of interests regarding the publication of this paper.

\section{Acknowledgments}

Mrs. Deepa Prabhu acknowledges Manipal University for the fellowship and Chemistry Department, MIT Manipal, for laboratory facilities.

\section{References}

[1] A. P. Schweitzer, Metallic Materials Physical, Mechanical, and Corrosion Properties, Marcel Dekker, New York, NY, USA, 2003.

[2] C. Vargel, Corrosion of Aluminium, Elsevier, London, UK, 2004.

[3] E. E. Stansbury and R. A. Buchanan, Fundamentals of Electrochemical Corrosion, ASM International Materials Park, Materials Park, Ohio, USA, 2000.

[4] H. P. Godard, W. B. Jepson, M. R. Bothwell, and R. L. Kane, The Corrosion of Light Metals, Wiley, New York, NY, USA, 1967.

[5] Z. Grubač, R. Babić, and M. Metikoš-Huković, "Application of substituted $\mathrm{N}$-arylpyrroles in the corrosion protection of aluminium in hydrochloric acid," Journal of Applied Electrochemistry, vol. 32, no. 4, pp. 431-438, 2002.

[6] M. A. Amin, Q. Mohsen, and O. A. Hazzazi, "Synergistic effect of I-ions on the corrosion inhibition of $\mathrm{Al}$ in $1.0 \mathrm{M}$ phosphoric acid solutions by purine," Materials Chemistry and Physics, vol. 114, no. 2-3, pp. 908-914, 2009.

[7] A. S. Fouda, M. Abdallah, I. S. Ahmed, and M. Eissa, "Corrosion inhibition of aluminum in $1 \mathrm{M} \mathrm{H}_{3} \mathrm{PO}_{4}$ solutions by ethanolamines," Arabian Journal of Chemistry, vol. 5, pp. 297$307,2010$.

[8] X. Li, S. Deng, and H. Fu, "Sodium molybdate as a corrosion inhibitor for aluminium in $\mathrm{H}_{3} \mathrm{PO}_{4}$ solution," Corrosion Science, vol. 53, no. 9, pp. 2748-2753, 2011.

[9] A. S. Fouda, A. A. Al-Sarawy, F. S. Ahmed, and H. M. ElAbbasy, "Corrosion inhibition of aluminum 6063 using some pharmaceutical compounds," Corrosion Science, vol. 51, no. 3, pp. 485-492, 2009.

[10] X. Li and S. Deng, "Inhibition effect of Dendrocalamus brandisii leaves extract on aluminum in $\mathrm{HCl}, \mathrm{H}_{3} \mathrm{PO}_{4}$ solutions," Corrosion Science, vol. 65, pp. 299-308, 2012.

[11] E. Kalman, "Inhibitors of low toxicity for aqueous solution," in Proceedings of 7th European Symposium on Corrosion Inhibitors (SIEC '90), Ferrara, Italy, September 1990.

[12] B. Sanyal, "Organic compounds as corrosion inhibitors in different environments-a review," Progress in Organic Coatings, vol. 9, no. 2, pp. 165-236, 1981.

[13] I. B. Obot, E. E. Ebenso, and Z. M. Gasem, "Eco-friendly corrosion inhibitors: adsorption and inhibitive action of ethanol extracts of chlomolaena odorata 1 . For the corrosion of mild steel in H2So4 solutions," International Journal of Electrochemical Science, vol. 7, no. 3, pp. 1997-2008, 2012.

[14] M. Sangeetha, S. Rajendran, J. Sathiyabama et al., "Corrosion inhibition by an aqueous extract of Phyllanthus amarus," Portugaliae Electrochimica Acta, vol. 29, no. 6, pp. 429-444, 2011.

[15] S. K. Sharma, G. Jain, J. Sharma, and A. Mudhoo, "Corrosion inhibition behaviour of azardirachta indica (neem) leaves extract as a green corrosion inhibitor for zinc in hydrochloric acid: a preliminary study," International Journal of Applied Chemistry, vol. 6, no. 1, pp. 83-94, 2010.

[16] N. O. Eddy, F. Awe, and E. E. Ebenso, "Adsorption and inhibitive properties of ethanol extracts of leaves of Solanum melongena for the corrosion of mild steel in $0.1 \mathrm{M} \mathrm{HCl}$," International Journal of Electrochemical Science, vol. 5, no. 12, pp. 1996-2011, 2010.

[17] S. K. Sharma, A. Mudhoo, G. Jain, and J. Sharma, "Corrosion inhibition and adsorption properties of azadirachta indica mature leaves extract as green inhibitor for mild steel in $\mathrm{HNO}_{3}$," Green Chemistry Letters and Reviews, vol. 3, no. 1, pp. 7-15, 2010.

[18] N. O. Eddy and E. E. Ebenso, "Corrosion inhibition and adsorption properties of ethanol extract of Gongronema latifolium on mild steel in $\mathrm{H}_{2} \mathrm{SO}_{4}$," Pigment and Resin Technology, vol. 39, no. 2, pp. 77-83, 2010.

[19] B. E. A. Rani and B. B. J. Basu, "Green inhibitors for corrosion protection of metals and alloys: an overview," International Journal of Corrosion, vol. 2012, Article ID 380217, 15 pages, 2012.

[20] P. B. Raja and M. G. Sethuraman, "Natural products as corrosion inhibitor for metals in corrosive media-a review," Materials Letters, vol. 62, no. 1, pp. 113-116, 2008.

[21] M. Sangeetha, S. Rajendran, T. S. Muthumegala, and A. Krishnaveni, "Green corrosion inhibitors-an overview," Protection of Materials, vol. 52, no. 1, pp. 3-19, 2011.

[22] D. Prabhu and R. Padmalatha, "Corrosion inhibition of 6063 aluminum alloy by Coriandrum sativum L seed extract in phosphoric acid medium," Journal Material Environment Science, vol. 4, no. 5, pp. 732-743, 2013. 
[23] D. Prabhu and P. Rao, "Coriandrum sativum L. - a novel green inhibitor for the corrosion inhibition of aluminum in $1.0 \mathrm{M}$ phosphoric acid solution," Journal of Chemical and Environmental Engineering, vol. 1, no. 4, pp. 676-683, 2013.

[24] S. Padhye, A. Ahmad, N. Oswal, and F. H. Sarkar, "Emerging role of Garcinol, the antioxidant chalcone from Garcinia indica Choisy and its synthetic analogs," Journal of Hematology \& Oncology, vol. 2, article 38, 2009.

[25] S. S. Handa, S. S. Khanuja, G. Longo, and D. Rakesh, Extraction Technologies for Medicinal and Aromatic Plants, International Centre for Science and High Technology, Trieste, Italy, 2008.

[26] F. Bentiss, M. Outirite, M. Traisnel et al., "Improvement of corrosion resistance of carbon steel in hydrochloric acid medium by 3,6-bis(3-pyridyl)pyridazine," International Journal of Electrochemical Science, vol. 7, no. 2, pp. 1699-1723, 2012.

[27] P. C. Okafor, V. E. Ebiekpe, C. F. Azike, G. E. Egbung, E. A. Brisibe, and E. E. Ebenso, "Inhibitory action of Artemisia annua extracts and artemisinin on the corrosion of mild steel in $\mathrm{H}_{2} \mathrm{SO}_{4}$ solution," International Journal of Corrosion, vol. 2012, Article ID 768729, 8 pages, 2012.

[28] U. M. Eduok, S. A. Umoren, and A. P. Udoh, "Synergistic inhibition effects between leaves and stem extracts of Sida acuta and iodide ion for mild steel corrosion in $1 \mathrm{M} \mathrm{H}_{2} \mathrm{SO}_{4}$ solutions," Arabian Journal of Chemistry, vol. 5, no. 3, pp. 325-337, 2010.

[29] A. J. Trowsdale, B. Noble, S. J. Harris, I. S. R. Gibbins, G. E. Thompson, and G. C. Wood, "The influence of silicon carbide reinforcement on the pitting behaviour of aluminium," Corrosion Science, vol. 38, no. 2, pp. 177-191, 1996.

[30] C. M. A. Brett, "The application of electrochemical impedance techniques to aluminium corrosion in acidic chloride solution," Journal of Applied Electrochemistry, vol. 20, no. 6, pp. 1000-1003, 1990.

[31] J. H. W. De Wit and H. J. W. Lenderink, "Electrochemical impedance spectroscopy as a tool to obtain mechanistic information on the passive behaviour of aluminium," Electrochimica Acta, vol. 41, no. 7-8, pp. 1111-1119, 1996.

[32] H. J. W. Lenderink, M. V. D. Linden, and J. H. W. De Wit, "Corrosion of aluminium in acidic and neutral solutions," Electrochimica Acta, vol. 38, no. 14, pp. 1989-1992, 1993.

[33] S. E. Frers, M. M. Stefenel, C. Mayer, and T. Chierchie, "ACImpedance measurements on aluminium in chloride containing solutions and below the pitting potential," Journal of Applied Electrochemistry, vol. 20, no. 6, pp. 996-999, 1990.

[34] W. J. Lorenz and F. Mansfeld, "Determination of corrosion rates by electrochemical DC and AC methods," Corrosion Science, vol. 21, no. 9-10, pp. 647-672, 1981.

[35] A. M. Abdel-Gaber, B. A. Abd-El-Nabey, I. M. Sidahmed, A. M. El-Zayady, and M. Saadawy, "Inhibitive action of some plant extracts on the corrosion of steel in acidic media," Corrosion Science, vol. 48, no. 9, pp. 2765-2779, 2006.

[36] S. S. Shivakumar and K. N. Mohana, "Studies on the inhibitive performance of cinnamomum zeylanicum extracts on the corrosion of mild steel in hydrochloric acid and sulphuric acid media," Journal of Materials and Environmental Science, vol. 4, no. 3, pp. 448-459, 2013.

[37] F. Bentiss, M. Lebrini, and M. Lagrenée, “Thermodynamic characterization of metal dissolution and inhibitor adsorption processes in mild steel/2,5-bis(n-thienyl)-1,3,4-thiadiazoles/ hydrochloric acid system," Corrosion Science, vol. 47, no. 12, pp. 2915-2931, 2005.
[38] M. A. Hegazy, H. M. Ahmed, and A. S. El-Tabei, "Investigation of the inhibitive effect of p-substituted 4-(N,N,N-dimethyldodecylammonium bromide)benzylidene-benzene-2-ylamine on corrosion of carbon steel pipelines in acidic medium," Corrosion Science, vol. 53, no. 2, pp. 671-678, 2011.

[39] R. K. Hart, "The formation of films on aluminium immersed in water," Transactions of the Faraday Society, vol. 53, pp. 10201027, 1957.

[40] J. Ishwara Bhat and V. D. P. Alva, "A study of aluminium corrosion inhibition in acid medium by an antiemitic drug," Transactions of the Indian Institute of Metals, vol. 64, no. 4-5, pp. 377-384, 2011.

[41] O. K. Abiola, A. O. C. Aliyu, A. A. Phillips, and A. O. Ogunsipe, "The effects of Phyllanthus amarus extract on corrosion and kinetics of corrosion process of aluminium in $\mathrm{HCl}$ solution," Journal of Materials and Environmental Science, vol. 4, no. 3, pp. 370-373, 2013.

[42] S. V. Lamakaa, M. L. Zheludkevicha, K. A. Yasakaua, M. F. Montemorb, and M. G. S. Ferreira, "High effective organic corrosion inhibitors for 2024 aluminium alloy," Electrochemica Acta, vol. 52, no. 25, pp. 7231-7247, 2007. 

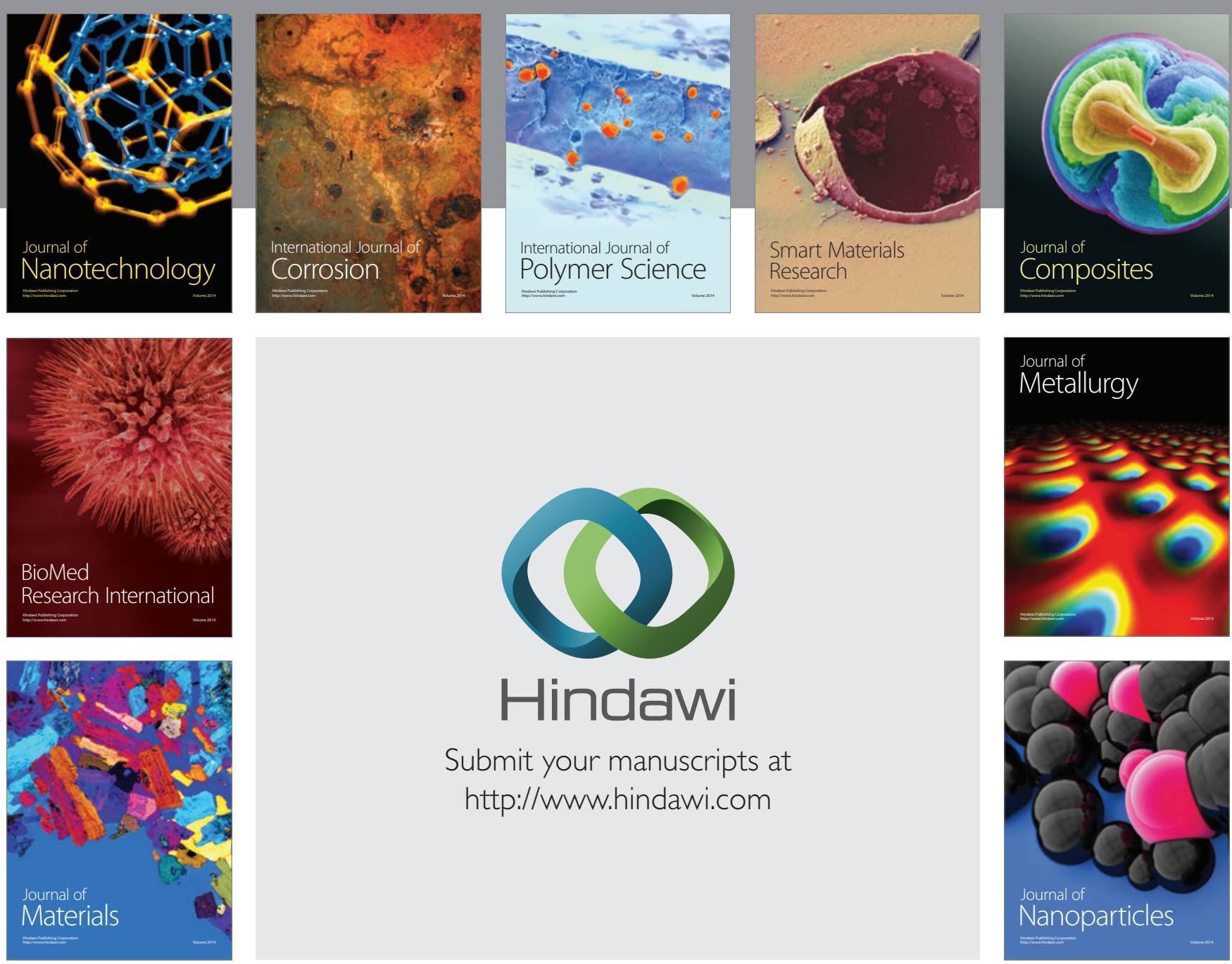

Submit your manuscripts at http://www.hindawi.com
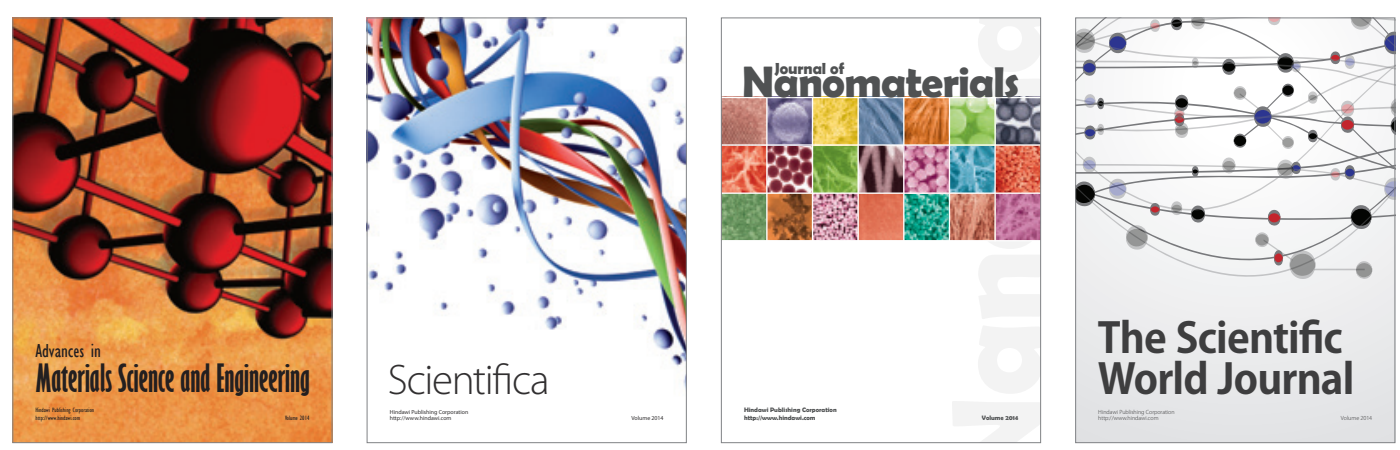

\section{The Scientific World Journal}
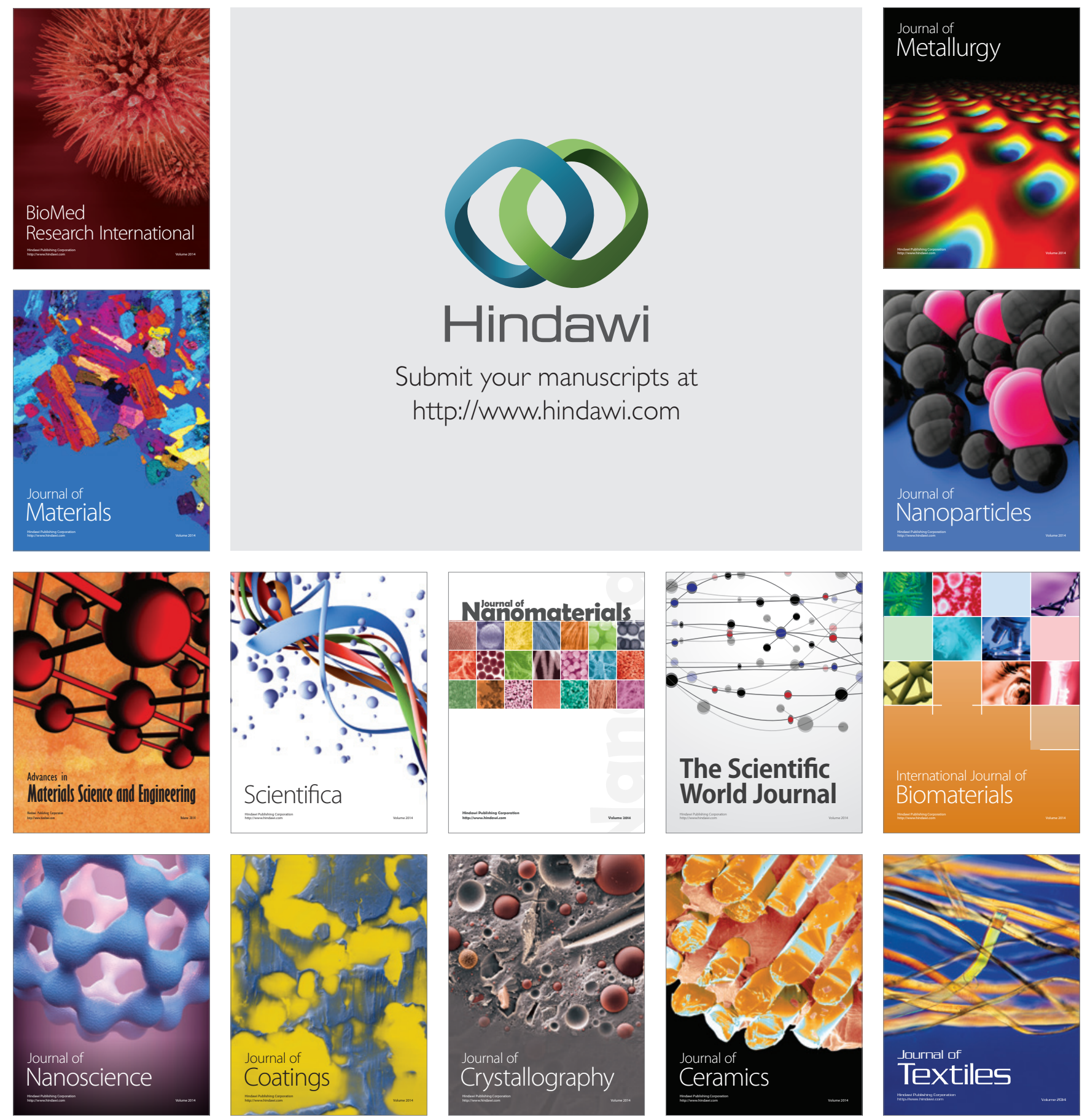